\title{
Implementasi Data Mining Menggunakan Regresi Linier Berganda dalam Memprediksi Jumlah Nasabah Kredit Macet Pada BPR Tanjung Morawa
}

\author{
Rudi Gunawan \\ STMIK Triguna Dharma
}

\begin{tabular}{l}
\hline \hline Article Info \\
\hline Article history: \\
Received Okt 22, 2018 \\
Revised Jan 18, 2019 \\
Accepted Feb 07, 2019
\end{tabular}

Keyword:

Bank Pengkreditan Rakyat

Kredit Macet

Regresi Linier Berganda

\begin{abstract}
Bank Pengkreditan Rakyat (BPR) merupakan salah satu jenis yang dikenal melayani golongan pengusaha mikro, kecil, dan menengah dengan lokasi yang pada umumnya dekat dengan masyarakat yang membutuhkan. Industri perbankan merupakan sektor penting dalam pembangunan maupun dalam pemodalan dalam usaha dan dipandang sebagai inti dari sistem perekonomian.Penyaluran dana yang dilakukan oleh bank dalam bentuk kredit atau bentuk-bentuk lainnya dalam rangka meningkatkan taraf hidup rakyat banyak memiliki peranan yang sangat penting dalam perekonomian.Banyaknya nasabah-nasabah dalam penyaluran kredit atau perbankan juga akan banyak terjadi masalah-masalah dalam pinjaman ataupun pengembalian pinjaman dana, maka dari itu pihak penyaluran kredit atau BPR harus siap menghadapi resiko kredit yang menyebabkan kredit tersebut menjadi bermasalah, atau bisa juga disebut dengan kredit macet. Data mining dalam memprediksi jumlah nasabah kredit macet dibangun bertujuan untuk mengetahui tingkat jumlah dari nasabah bermaslah atau bisa juga disebut dengan kredit macet dengan menerapkan metode regresi linier berganda. Diharapkan metode regresi linier berganda ini dapat menyelesaikan permasalahan di BPR NBP 33 Tanjung Morawa dalam menangani atau mengatasi nasabah yang bermasalah atau kredit macet dan dapat membantu pihak perusahaan dalam memprediksi jumlah kredit macet dalam perbulannya.
\end{abstract}

Copyright (C) 2019 STMIK Triguna Dharma. All rights reserved.

\section{PENDAHULUAN}

Bank Perkreditan Rakyat (BPR) merupakan lembaga perbankan resmi yang diatur berdasarkan UndangUndang No. 7 tahun 1992 tentang Perbankan dan sebagaimana telah diubah dengan Undang-Undang No. 10 tahun 1998. Dalam undang-undang tersebut secara jelas disebutkan bahwa ada dua jenis bank, yaitu Bank Umum dan BPR. Bank Perkreditan Rakyat yang biasa disebut juga dengan BPR adalah salah satu jenis bank yang dikenal melayani golongan pengusaha mikro, kecil dan menengah dengan lokasi yang pada umumnya dekat dengan tempat masyarakat yang membutuhkan. Fungsi BPR tidak hanya sekedar menyalurkan kredit kepada para pengusaha mikro, kecil dan menengah, tetapi juga menerima simpanan dari masyarakat. Dalam penyaluran kredit kepada masyarakat menggunakan prinsip 3T, yaitu Tepat Waktu, Tepat Jumlah, Tepat Sasaran, karena proses kreditnya relatif cepat, persyaratan lebih sederhana, dan sangat mengerti akan kebutuhan Nasabah.

Industri perbankan merupakan sektor penting dalam pembangunan maupun dalam pemodalan dalam usaha dan dipandang sebagai inti dari sistem perekonomian di setiap negara dimana arus ekonomi dan keuangan mengalir di dalamnya. Hal ini dikarenakan perbankan yang berfungsi sebagai financial Intermediary diantara pihak - pihak yang membutuhkan dana. Penyaluran dana dilakukan oleh bank dalam bentuk kredit atau bentuk-bentuk lainnya dalam rangka meningkatkan taraf hidup rakyat banyak memiliki peranan yang sangat penting dalam perekonomian. Kredit merupakan bagian terbesar dari aset yang dimiliki oleh bank yang bersangkutan. 
Dalam penyaluran kredit, bank harus siap menghadapi risiko kredit yang menyebabkan kredit tersebut menjadi bemasalah. Risiko kredit merupakan suatu risiko akibat kegagalan atau ketidak mampuan nasabah mengembalikan jumlah pinjaman yang diperoleh dari bank beserta bunganya sesuai dengan jangka waktu yang telah ditentukan. Maka dari itu diperlukannya karyawan-karyawan dalam BPR tersebut harus cermat menjalankan pekerjaannya tersebut agar dapat meningkatkan laba ataupun mengurangi kredit bermasalah ataupun kredit macet, dengan cara mengetahui terlebih dahulu tingkat atau jumlah kredit macet yang ada dalam perbulannya kemudian para karyawan dan atasannya dapat merundingkan ataupun membawa masalah tersebut kedalam rapat, agar perusahaan tersebut juga mengetahui peningkatan-peningkatan perusahaan tersebut dalam penyaluran pinjaman dana. untuk mengurangi resiko terjadinya kredit bermasalah ataupun kredit macet, maka dari itu digunakannya metode Regresi Linier Berganda sehingga dapat membantu perkembangan berjalannya Bank Perkreditan Rakyat dengan lancar untuk menyalurkan kredit-kredit selanjutnya kepada para pengusaha-pengusaha mikro, kecil dan menengah. Sehingga dapat saling membantu satu sama lain, dapat membantu perusahaan BPR tersebut juga membantu para peminjam ataupun nasabah yang tidak mampu dalam hal melunasi kredit pinjaman

\section{LANDASAN TEORI}

\subsection{Data Mining}

Data Mining adalah sebagai proses untuk mendapatkan informasi yang berguna dari gudang basis data yang besar. Data Mining juga dapat diartikan sebagai pengekstrkan informasi baru yang diambil dari bongkahan data besar yang membantu dalam pengambilan keputusan. Istilah Data Mining kadang disebut juga knowledge discovery (Prasetyo, $2012: 2$ ).

Menurut Fajar Astuti Hermawati (2009:3) Data Mining merupakan proses iteratif dan interaktif untuk menentukan pola atau model baru yang sahih (sempurna), bermanfaat dan dapat dimengerti dalam suatu database yang sangat besar (massive database)

Eko Prasetyo (2014:5) 4Dalam data mining pekerjaan yang berkaitan dapat dibagi menjadi empat kelompok yaitu: model prediksi (prediction modeling), analisis cluster (cluster analysis), analisis assosiasi (association analysis), dan deteksi anomali (anomaly detection).

\subsection{Regresi Linier Berganda}

Ada dua jenis regresi linier yaitu regresi linier sederhana dengan regresi linier berganda. Secara sederhana, dapat dikatakan bahwa regresi linier sederhana hanya melibatkan satu variabel pemberi pengaruh, sementara regresi linier berganda melibatkan lebih dari satu variabel pemberi pengaruh (Santoso dan Suryadi, 2010:33). Manfaat dari hasil analisis regresi adalah untuk membuat keputusan apakah naik dan menurunnya variabel dependen dapat dilakukan melalui pringkatan variabel independen atau tidak. Sebagai contoh, naiknya jumlah penjualan dapat dilakukan melalui jumlah iklan atau tidak (Sugiyono 2011:260).

Menurut Hermawati (2013:16) memprediksi nilai dari suatu variabel kontinyu yang diberikan berdasarkan nilai vaariabel yang lain, dengan mengasumsikan sebuah model ketergantungan linier atau nonlinier. Teknik ini banyak dipelajari dalam statistika, bidang jaringan syaraf tiruan (neural network).

Dalam regresi linear terdapat dua jenis regresi linear yaitu Regresi Linier Sederhana dan Regresi Linear Berganda. Secara sederhana, dapat dikatakan bahwa regresi linear sederhana hanya melibatkan satu variabel pemberi pengaruh, sementara regresi linear berganda melibatkan lebih dari satu variabel pemberi pengaruh. Jadi analisis regresi ganda akan dilakukan bila junlah variable independennya minimal 2. Persamaan regresi untuk dua prediktor adalah: $\mathrm{Y}=\mathrm{a}+\mathrm{b}_{1} \mathrm{X}_{1}+\mathrm{b}_{2} \mathrm{X}_{2}$

\section{PEMBAHASAN DAN HASIL}

Data akan diolah dengan menerapkan data mining dengan penggunaan metode regresi linier berganda dalam proses untuk memprediksi nasabah kredit macet. Beberapa atribut atau komponen variabel yang digunakan

Tebel 1 LaporanNasabah Kredit Macet BPR

\begin{tabular}{|c|c|c|c|c|}
\hline Bulan & Nasabah & Total Pinjaman & Suku Bunga & Kredit Macet \\
\hline Januari & 45 & 480000000 & 124800000 & 7 \\
\hline Februari & 28 & 320000000 & 83200000 & 4 \\
\hline Maret & 35 & 400000000 & 104000000 & 5 \\
\hline April & 38 & 580000000 & 150800000 & 6 \\
\hline Mei & 43 & 600000000 & 156000000 & 8 \\
\hline
\end{tabular}




\begin{tabular}{|c|c|c|c|c|}
\hline Juni & 51 & 510000000 & 132600000 & 10 \\
\hline Juli & 67 & 750000000 & 195000000 & 15 \\
\hline Agustus & 60 & 720000000 & 187200000 & 12 \\
\hline September & 77 & 980000000 & 254800000 & 9 \\
\hline Oktober & 64 & 700000000 & 182000000 & 11 \\
\hline November & 50 & 480000000 & 124800000 & 9 \\
\hline Desember & 33 & 300000000 & 78000000 & 110 \\
\hline Jumlah & 591 & 6820000000 & 1773200000 & Sumber: BPR Lubuk Pakam
\end{tabular}

Tabel 2 Laporan Nasabah Kredit Macet BPR Yang Dinormalisasi (dalam ribuan)

\begin{tabular}{|c|c|c|c|c|}
\hline Bulan & $\begin{array}{c}\text { Nasabah } \\
\left(\mathbf{X}_{\mathbf{1}}\right)\end{array}$ & $\begin{array}{c}\text { Total Pinjaman } \\
\left(\mathbf{X}_{\mathbf{2}}\right)\end{array}$ & $\begin{array}{c}\text { Suku Bunga } \\
\left(\mathbf{X}_{3}\right)\end{array}$ & $\begin{array}{c}\text { Kredit } \\
\text { Macet } \\
(\mathbf{Y}\end{array}$ \\
\hline Januari & 0,0045 & 48000 & 12480 & 0,0007 \\
\hline $\begin{array}{c}\text { Februar } \\
\text { i }\end{array}$ & 0,0028 & 32000 & 8320 & 0,0004 \\
\hline Maret & 0,0035 & 40000 & 10400 & 0,0005 \\
\hline April & 0,0038 & 58000 & 15080 & 0,0008 \\
\hline Mei & 0,0043 & 60000 & 13260 & 0,0006 \\
\hline Juni & 0,0051 & 51000 & 19500 & 0,001 \\
\hline Juli & 0,0067 & 75000 & 18720 & 0,0015 \\
\hline Agustus & 0,006 & 72000 & 25480 & 0,0012 \\
\hline September & 0,0077 & 98000 & 18200 & 0,0014 \\
\hline Oktober & 0,0064 & 70000 & 12480 & 0,0011 \\
\hline November & 0,005 & 48000 & 7800 & 0,0009 \\
\hline Desember & 0,0033 & 30000 & 177320 & 0,011 \\
\hline Jumlah & 0,0591 & 682000 & & \\
\hline Persaman & & & 15600 \\
\hline
\end{tabular}

Persamaan regresi untuk tiga prediktor adalah:

Untuk mencari koefisien regresi $b_{1}, b_{2}, b_{3}$, dan a digunakan persamaan simultan sebagai berikut:

1. $\sum \mathrm{X}_{1} \mathrm{Y}=\mathrm{b}_{1} \sum \mathrm{X}_{1}^{2}+\mathrm{b}_{2} \sum \mathrm{X}_{1} \mathrm{X}_{2}+\mathrm{b}_{3} \sum \mathrm{X}_{1} \mathrm{X}_{3}$

2. $\sum \mathrm{X}_{2} \mathrm{Y}=\mathrm{b}_{1} \sum \mathrm{X}_{1} \mathrm{X}_{2}+\mathrm{b}_{2} \sum \mathrm{X}_{2}^{2}+\mathrm{b}_{3} \sum \mathrm{X}_{2} \mathrm{X}_{3}$

3. $\sum \mathrm{X}_{3} \mathrm{Y}=\mathrm{b}_{1} \sum \mathrm{X}_{1} \mathrm{X}_{3}+\mathrm{b}_{2} \sum \mathrm{X}_{2} \mathrm{X}_{3}+\mathrm{b}_{3} \sum \mathrm{X}_{3}^{2}$

$\mathrm{a}=\overline{\mathrm{Y}}-\mathrm{b}_{1} \overline{\mathrm{X}}_{1}-\mathrm{b}_{2} \overline{\mathrm{X}}_{2}-\mathrm{b}_{3} \overline{\mathrm{X}}_{3}$

Hasil skor deviasi dimasukkan kedalam persamaan simultan:

$0,000004825=0,0000252425 b_{1}+301,35 b_{2}+78,351 b_{3} \quad \ldots \ldots \ldots \ldots$ (1)

$53,53333333=301,35 b_{1}+4249666667 b_{2}+1104913333 b_{3} \quad \ldots \ldots \ldots \ldots$ (2)

$13,91866667=78,351 b_{1}+1104913333 b_{2}+287277466,7 b_{3} \quad \ldots \ldots \ldots \ldots$. (3)

Setelah persamaan regresi linier didapatkan, maka untuk memprediksi nasabah kredit macet akan sangat mudah. Contoh kasus misalnya pada bulan berikutnya jumlah Nasabah $\left(\mathrm{X}_{1}\right)$ yang ada sebanyak $41(0,0041)$, Total Pinjaman $\left(\mathrm{X}_{2}\right)$ sebanyak 550000000(55000), dan Suku Bunga ( $\left.\mathrm{X}_{3}\right)$ sebanyak 143000000(14300). Maka menghitung prediksi jumlah nasabah kredit macet adalah dengan menggunakan persamaan regresi linier berganda diatas, sehingga:

$\mathrm{Y}=\mathrm{a}+\mathrm{b}_{1} \cdot \mathrm{x}_{1}+\mathrm{b}_{2} \cdot \mathrm{x}_{2}+\mathrm{b}_{3} \cdot \mathrm{x}_{3}$

$\mathrm{Y}=-3,69699 \mathrm{E}-05+0,265629921740063(0,0041)+-0000000196(55000)+0,0000000515(14300)$

$\mathrm{Y}=-3,69699 \mathrm{E}-05+0,001089083+-0,001080123+0,00073697$

$\mathrm{Y}=0,00070896 \times 10.000$ 
$\mathrm{Y}=7,089603952=7$ Kredit Macet

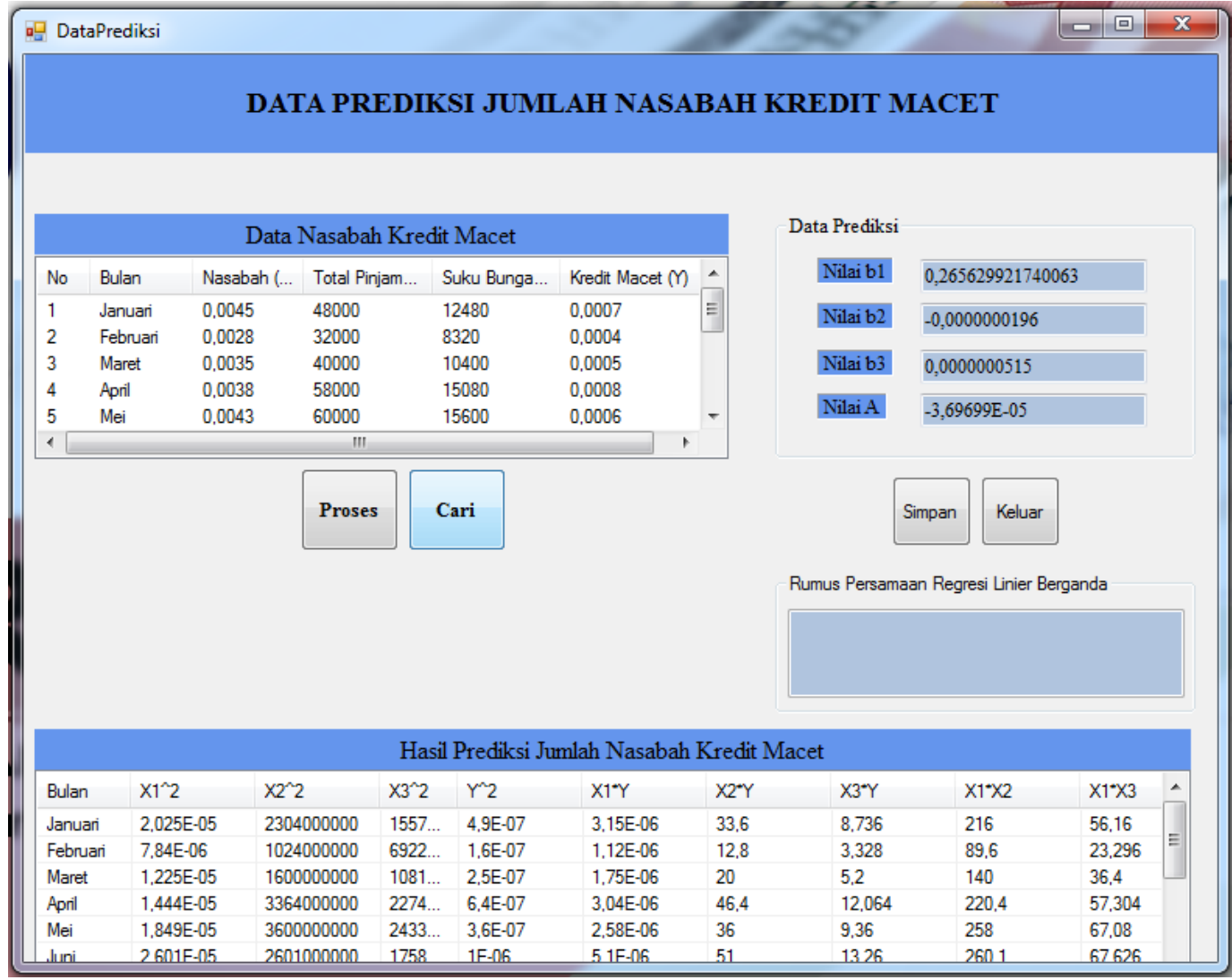

Gambar 1 Tampilan Form Data Prediksi

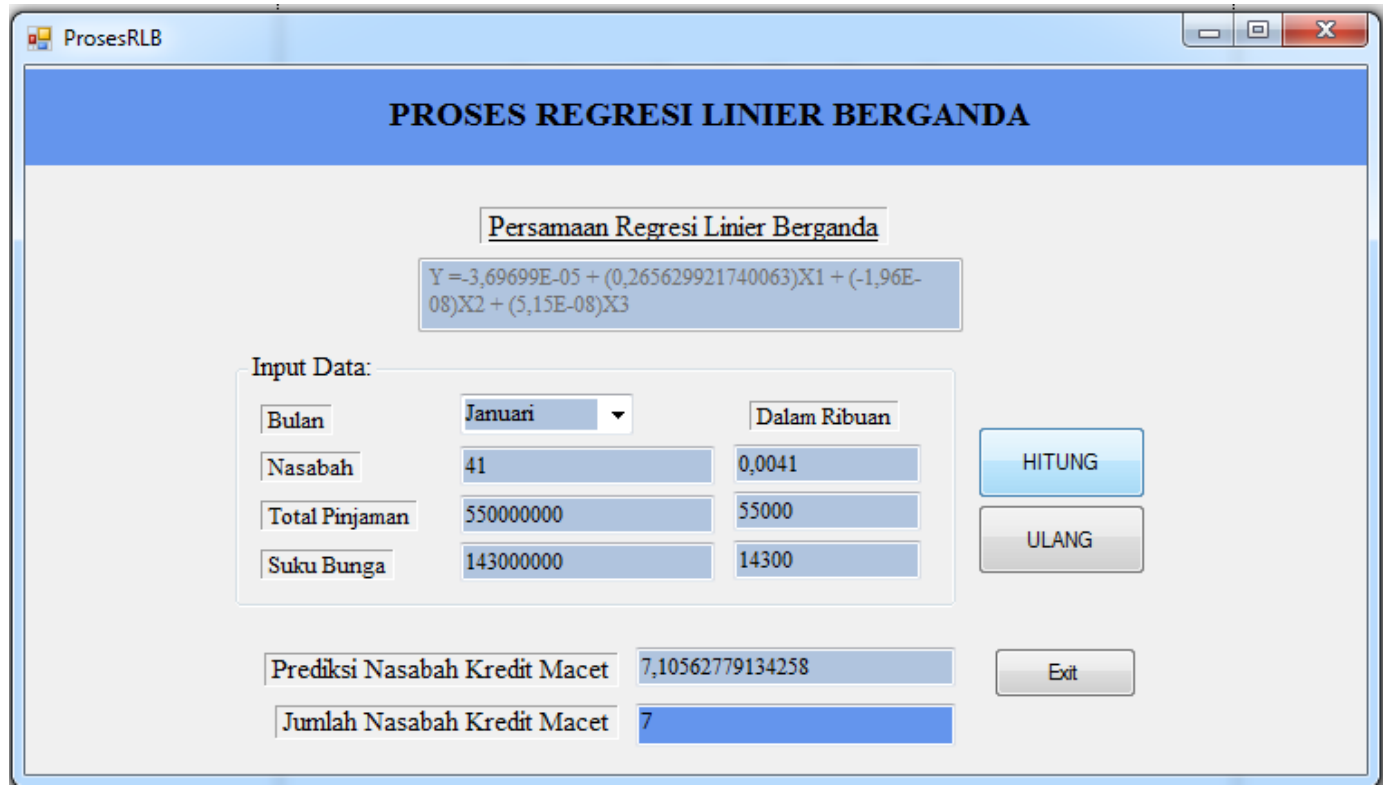

Gambar 2 Hasil Proses Regresi Linier Berganda

\section{KESIMPULAN}

Berdasarkan dari penelitian yang telah dilaksanakan dan sudah diuraikan dalam Implementasi Data Mining Menggunakan Regresi Linier Berganda dalam Memprediksi Jumlah Nasabah Kredit Macet Pada BPR Tanjung Morawa, maka dapat diambil kesimpulan sebagai berikut:

1. Berdasarkan anlisa untuk memprediksi jumlah kredit macet, maka dibutuhkan sebuah sistem yang mampu memprediksi jumlah nasabah kredit macet, maka dari itu dirancang sebuah sistem yang mampu 
mengadopsi/menerapkan metode regresi linier berganda sehingga dapat membantu pihak perusahaan khususnya admin untuk menentukan prediksi jumlah nasabah kredit macet dengan cepat dan efisien.

2. Dalam merancang sistem Data Mining yang mampu memprediksi jumlah nasabah kredit macet terlebih dahulu menentkuan variabel, menghitung estimasi laporan kredit macet BPR, menghitung data koefisien dan persamaan regresi, kemudian mendapatkan hasil persamaan regresi.

3. Sistem ini dapat diterpkan atau diimplementasikan untuk memprediksi jumlah nasabah kredit macet di BPR menggunakan metode regresi linier berganda.

\section{REFERENSI}

Hendrayudi. (2011). Dasar-dasar Microsoft Visual Basic Studio 2008. Bandung: Satu Nusa Hermawati, F. A. (2013). Data Mining. Yogyakarta : Andi

https://id.wikipedia.org/wiki/Microsoft_Access

Prasetyo, E.(2012).Data Mining Konsep dan Aplikasi Menggunakan Matlab. Yogyakarta : Andi

Shalahuddin, R. A,S, M. (2013). Rekayasa Perangkat Lunak. Bandung: Informatika

Sugiyono, DR. (2011). Statistika Untuk Penelitian. Bandung: Alfabeta

Susanto, S \& Suryadi, D. (2010). Pengantar Data Mining menggali pengetahuan dari bongkahan data.

Yogyakarta : Andi

Winpec Solution, 2008, Microsoft Access 2007 Untuk Tingkat Mahir. Jakarta: PT. Elex Media Komputindo Kelompok Gramedia Anggota IKAPI. 